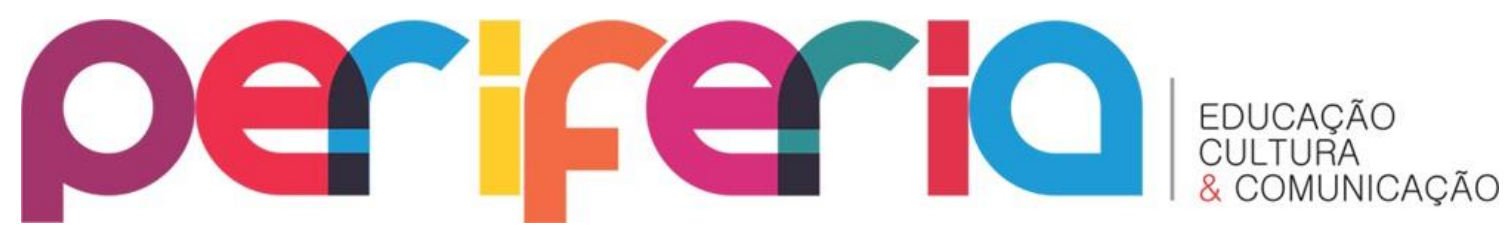

ISSN:1984-9540

DOI: $10.12957 /$ periferia.2020.55046

\title{
PREZADO AFILHADO JOSÉ, RECEBI SUA CARTA, QUE LI COM A MAIOR ATENÇÃO: ESCRITOS DA GOMÉIA A JOSÉ DANIEL DAS NEVES (1948-1972)
}

Andrea Mendes ${ }^{1}$

\section{Resumo}

O presente artigo se propõe a apresentar uma seleção de correspondências pertencentes à coleção particular de José Daniel das Neves (1937-2009), conhecido no culto como Tata Lemba Nanguê, Ogan José Daniel ou simplesmente Zé Daniel da Goméia. Sendo até hoje uma das grandes referências da Goméia, apadrinhado e confirmado no candomblé por Joãozinho, em Salvador, José Daniel agrupou uma pequena série de cartas endereçadas a ele ou à sua mãe, enviadas por Joãozinho e outras pessoas vinculadas à Goméia, formando um acervo composto, além das cartas, por recortes de jornais e revistas, fotografias e outros elementos ligados à memória de seu padrinho e tata de inquice. A carta, comumente utilizada como meio de comunicação, é um gênero de escrita cuja importância ultrapassa a função meramente comunicativa, e que oscila no fio tênue que divide os limites fronteiriços entre o público e o privado. Para além do fato de conter elementos ligados à vida privada dos personagens envolvidos, a escrita epistolar pode servir como fonte para a pesquisa histórica, revelando particularidades do cotidiano dos correspondentes em questão, bem como de seu entorno e contexto histórico, a partir de fragmentos que podem ser extraídos e confrontados com outras fontes documentais. Esses fragmentos, como pequenos indícios apontados por Carlo Ginzburg no exercício da pesquisa histórica, podem servir como recurso valioso na busca da compreensão sobre o percurso de Joãozinho e sua comunidade religiosa.

Palavras-chave: Joãozinho da Goméia; Arquivos pessoais; Escrita epistolar

\footnotetext{
${ }^{1}$ Doutora em História Social da África - IFCH - UNICAMP. Autora de "Vestidos de Realeza": Fios e nós centro-africanos no candomblé de Joãozinho da Goméia. Série Recôncavo da Guanabara, vol. 1. Duque de Caxias, RJ: APPH - Clio, 2014. ORCID iD: https://orcid.org/0000-0002-3902-2835. E-mail: andreamendeskaya@gmail.com
}

Periferia, v. 12, n. 3, p. 14-38, set./dez. 2020 


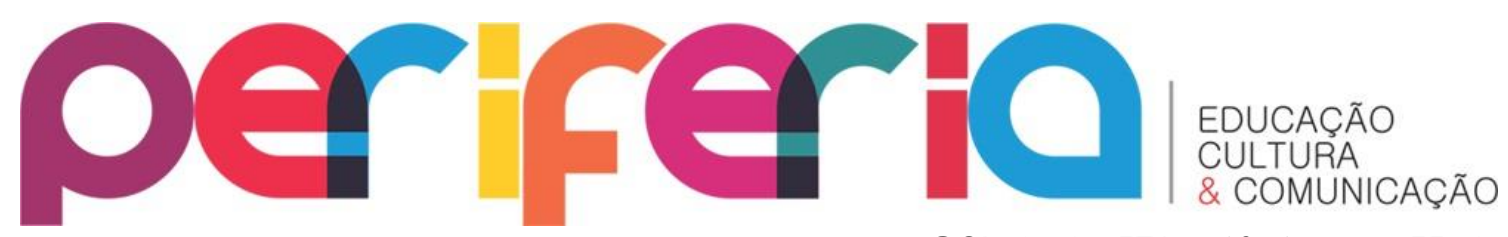

ISSN:1984-9540

DOI: $10.12957 /$ periferia. 2020.55046

DEAR GODSON JOSÉ, I RECEIVED YOUR LETTER, WHICH I READ WITH GREAT ATTENTION: LETTERS FROM GOMÉIA TO JOSÉ DANIEL DAS NEVES (1948-1972)

\section{Abstract}

This article proposes to introduce a selection of personal letters of José Daniel das Neves' private fund. He has known as Tata Lemba Nanguê, Ogan José Daniel or simply Zé Daniel da Goméia. José Daniel was one of great references of Goméia and Joãozinho was his godfather and confirmed his position in candomblé. José Daniel grouped a small series of letters sent by Joãozinho and other people linked to Goméia to him and his mother. This collection is composed, in addition to letters, of newspapers and magazine clippings, photographs and other elements linked to the memory of his godfather and tata de inquice. The letter is a genre of writing whose importance goes beyond the merely communicative function, which oscillates in a fine thread that divides boundaries between public and private. Epistolary writing can serve as a source for historical research, which reveal particularities in daily lives of the correspondents in question, as well as their surroundings and historical context, from fragments that can be extracted and compared with other documentary sources. These fragments are thought, in according with Carlo Ginzburg, as small indications in the exercise of historical research. They can serve as a valuable resource to search meanings about Joãozinho's journey and his religious community.

Keywords: Joãozinho da Goméia; Personal archives; Epistolary writing

\section{QUERIDO AHIJADO JOSÉ, RECIBÍ TU CARTA, QUE LEÍ CON LA MAYOR ATENCIÓN: ESCRITOS DE GOMÉIA A JOSÉ DANIEL DAS NEVES (1948-1972)}

\section{Resumen}

El presente artículo propone presentar una selección de correspondencias personales pertenecientes a la colleción personal de José Daniel das Neves (1937-2009), conocido en el culto como Tata Lemba Nanguê, Ogan José Daniel o simplemente Zé Daniel da Goméia. Habiendo sido uno de los grandes referentes de Goméia, tomado como ahijado y confirmado en candomblé por Joãozinho, en Salvador, José Daniel agrupó una pequeña serie de cartas dirigidas a él o a su madre, enviadas por Joãozinho y otras personas relacionadas con la Goméia, formando una colección compuesta, además de cartas, por recortes de periódicos y revistas, fotografías y otros elementos vinculados a la memoria de su padrino y tata de inquice. La carta, comúnmente utilizada como medio de comunicación, es un género de escritura cuya importancia va más allá de la función meramente 


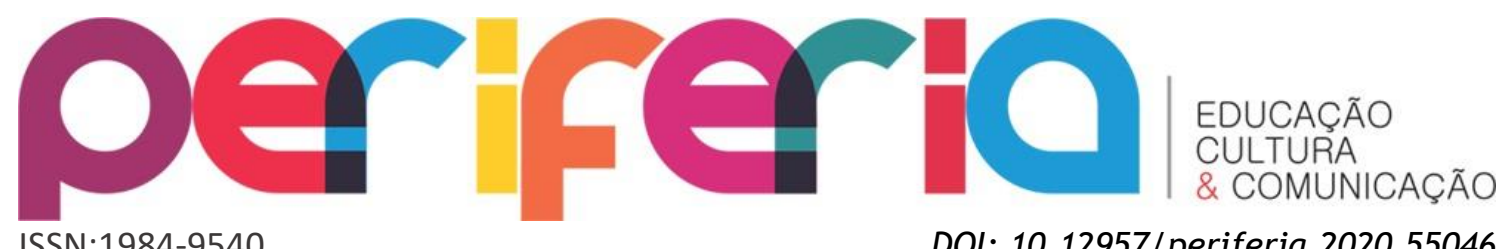

ISSN:1984-9540

DOI: 10.12957/periferia.2020.55046 comunicativa, y que oscila en el fino hilo que divide los límites entre lo público y lo privado. Además de contener elementos vinculados a la vida privada de los personajes, la escritura epistolar puede servir como fuente para la investigación histórica, revelando particularidades en la vida cotidiana de los corresponsales, así como su entorno y contexto histórico, a partir de fragmentos que se pueden extraer y comparar con otras fuentes documentales. Estos fragmentos, como pequeños indicios señalados por Carlo Ginzburg en el ejercicio de la investigación histórica, pueden ser un recurso valioso en la búsqueda de comprensión sobre el cotidiano de Joãozinho y su comunidad religiosa.

Palabras clave: Joãozinho da Goméia; Archivos personales; Escritura epistolar

Conheci o xicarangoma 2 José Daniel das Neves (Salvador - BA, 1937 Salvador - BA, 2009), ou Tata Zé Daniel, como era carinhosamente conhecido, no ano de 2004. Vindo de Salvador, ele esteve na cidade de Hortolândia, na região metropolitana de Campinas - SP para presidir um mukondo, cerimônia fúnebre do candomblé Angola. Ele carregava consigo uma antiga pasta, que abrigava recortes de jornais e revistas, fotografias, impressos, uma variedade de papéis que se relacionavam, de alguma forma, à memória de Joãozinho da Goméia, seu tata de inquice no candomblé e também seu padrinho de nascimento. Dentre esses papéis, alguns manuscritos: cartas enviadas a ele ou à sua mãe, Maria Florença dos Santos, comadre e filha de santo de Seu João, assinadas por ele mesmo ou por outras pessoas relacionadas à Goméia de Caxias.

A pasta plástica comum, em mau estado de conservação, pelo próprio manuseio, colocava em risco a integridade daqueles "papéis de memória". Soube depois que ele não se separava da pasta em circunstância alguma e que, mesmo viajando com frequência para realizar mukondos ${ }^{3} \mathrm{em}$ todo o país (ele era um dos grandes especialistas desse rito do candomblé Angola), pai

\footnotetext{
${ }^{2}$ Xicarangoma: chefe dos tocadores do engoma, ou tambor, nos candomblés Angola Congo; similar ao ogan alagbe, do candomblé ketu, ou do huntó, do candomblé jeje. (ALMEIDA apud MENDES, p. 68).

${ }^{3}$ Mukondo: rito fúnebre do candomblé Angola-Kongo.
}

Periferia, v. 12, n. 3, p. 14-38, set./dez. 2020 


\section{periferio}

Daniel costumava carregar o material consigo, o que arruinava ainda mais seu estado de conservação. Naquela circunstância, eu me ofereci para tentar acondicionar o material de forma menos danosa, ciente da importância daquele acervo, tanto do ponto de vista afetivo quanto do ponto de vista histórico. Ele concordou em deixar aquele material comigo por dois dias, para que fosse reorganizado e acondicionado, e consentiu também que eu digitalizasse o material, para que garantíssemos de algum modo mais um meio de armazenamento e conservação daquelas memórias. Sobre esse evento, um jovem tata que o acompanhava nessas funções, de quem não tenho registro do nome, mas cujo apelido era "Buiú", me disse na ocasião, com olhos espantados: “olha, pai Daniel gostou de você, viu? Porque ele não se separa nunca daquela pasta, e nem deixa que ninguém fique sozinho com ela sem a presença dele. Ele confia muito em você!”. Talvez aquele comentário tenha sido uma forma de sinalizar que eu deveria honrar a confiança em mim depositada, mais do que tudo. Finalmente, papéis minimamente higienizados, digitalizados e acondicionados em uma pasta-catálogo, retornaram às mãos de seu proprietário, juntamente com duas cópias da mídia que continha as digitalizações do acervo. Até o momento, desconhecemos qual foi a destinação desse acervo após o falecimento de pai Daniel.

Arquivos pessoais e seus respectivos documentos de uso privado se apresentam como fontes de grande potencial para a pesquisa histórica. As cartas pessoais, por seu caráter íntimo, são portadoras de narrativas sobre o cotidiano dos indivíduos envolvidos, mesmo que de modo descontínuo e fragmentado. Consideradas por muito tempo de menor importância dentre as fontes possíveis para perscrutar a história, cartas interessam pelo que podem indicar sobre o remetente, o destinatário e os contextos nos quais viviam; comportamentos, construção de redes de sociabilidade e apoio, além das relações afetivas propriamente ditas, com frequência presentes nesses documentos. Além de se prestarem como veículo de comunicação entre pessoas fisicamente distantes, revelam também estados emocionais, tanto 


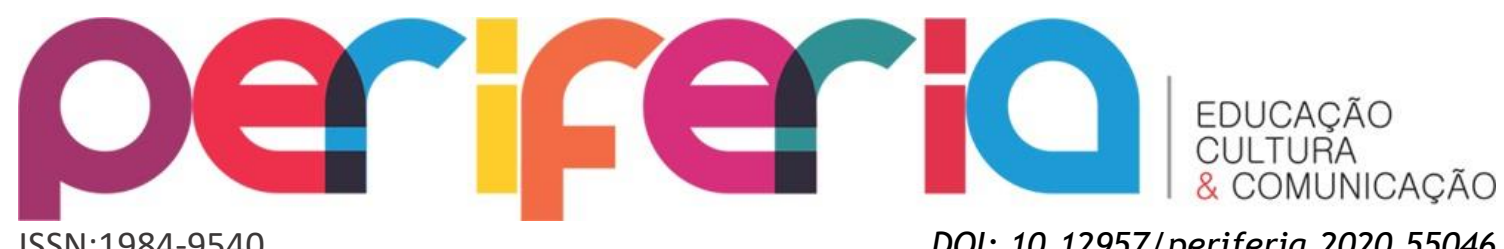

daqueles que redigem as cartas como, de algum modo, podemos vislumbrar sentimentos evocados naqueles que a recebem, trazendo indícios sutis sobre o passado que se deseja interpretar. As práticas de escrita de si podem destacar trajetórias individuais e coletivas, seus caminhos e alterações, e suas compartimentações em tempos diversos do cotidiano dos indivíduos. Essas escritas de si, que tem por característica principal o uso da primeira pessoa, singular ou plural, e que descortinam experiências individuais resguardadas do público em geral, embora sempre tenham sido utilizadas, apenas recentemente vêm sendo consideradas fonte privilegiada para a reflexão historiográfica. ${ }^{4}$ GOMES (2004 p.10) defende a necessidade de articular movimentos que constituam centros de pesquisa e documentação dedicados à guarda e conservação de arquivos privados/pessoais, tratados como fontes e, também, como objetos patrimoniais, sejam de indivíduos públicos ou não.

Cartas pessoais podem e devem ser interrogadas como indícios de criação de redes de sociabilidade, de organizações de indivíduos em torno de um grupo comum, seja ele representado por um indivíduo referencial, ou não. No caso específico da coleção de José Daniel das Neves, a figura de pai Joãozinho é a grande referência das relações, mesmo passados anos após sua morte. Esses pequenos indícios, ou rastros, combinados a fontes de outras naturezas, como registros de imprensa ou testemunhos orais, podem contribuir significativamente na interpretação sobre o passado do candomblé da Goméia, seu líder e seus adeptos. Essas correspondências são como pistas que podem conduzir as pesquisas sobre nosso personagem central, sua comunidade e o contexto social em que viviam. "Se a realidade é opaca, existem zonas privilegiadas - sinais, indícios - que permitem decifrá-la". (GINZBURG, 1989, p. 77)

\footnotetext{
${ }^{4}$ Sobre os usos da escrita epistolar e da escrita de si como fonte histórica, ver GOMES, Angela de Castro (org). Escrita de si, escrita da História. Rio de Janeiro: Fundação Getúlio Vargas, 2004, pp. 7 a 24
}

Periferia, v. 12, n. 3, p. 14-38, set./dez. 2020 


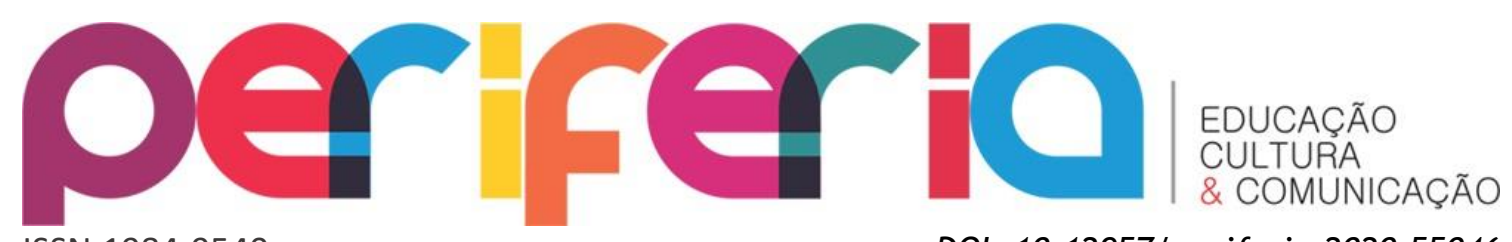

ISSN:1984-9540

DOI: $10.12957 /$ periferia.2020.55046

Escritos da Goméia: As cartas

As cartas que compõe o arquivo pessoal de José Daniel das Neves totalizam dez manuscritos, sem envelopes, selos ou carimbos de postagem e circulação; seis foram redigidas por Joãozinho da Goméia, duas por Antônio Motta, uma por Maria de Lurdes Ramos e uma por Maria Florença dos Santos, e o período compreendido entre as cartas vai de 1948 a 1978. Dentre as cartas de Joãozinho, redigidas entre os anos de 1957 e 1966 (contendo uma sem data), cinco foram endereçadas a Maria Florença, mãe de José Daniel, a quem Joãozinho chamava de Neném, e uma foi dirigida ao próprio José Daniel.

As cartas de Joãozinho eram breves e, na maioria das vezes, enviadas como resposta a outras que havia recebido anteriormente (“(...) respondo sua carta com atraso...", "Recebi sua carta...”, “(...) respondo sua carta de 9 de maio..."), o que sugere que esse era o meio mais usual para se comunicar com Maria Florença e outras pessoas de suas relações em Salvador. Em uma das cartas, ele aparentemente encaminha uma segunda carta para outra pessoa, Berenice, e no canto do papel pede que essa seja entregue à destinatária. Essas cartas curtas parecem indicar o cotidiano atarefado do pai de santo, e suas muitas atribuições nas atividades do terreiro. Tendo recolhido um barco com 19 yaôs ${ }^{5}$ em 1937 (feito muito comentado pela própria dificuldade de levar a cabo tal intento), ao que tudo indica Joãozinho continuou iniciando muitas filhas ao mesmo tempo, ao longo de sua vida como tata de inquice. 6 Embora o chamado "barco das 19" tenha ficado na memória do povo da Goméia7, outros barcos igualmente numerosos aconteceram; em 1965, Joãozinho fala de seu cotidiano atarefado, acumulando as obrigações

\footnotetext{
${ }^{5}$ Yaô, l̀yàwó: filha/o de santo, pessoa iniciada no candomblé.

${ }^{6}$ Tata de inquice, tata ria nkisi: Pai-de-santo, líder religioso do candomblé Angola-Kongo.

${ }^{7}$ Uma das integrantes desse barco de iniciação foi mãe Mirinha do Portão, líder do terreiro São Jorge Filho da Goméia, em Lauro de Freitas, região metropolitana de Salvador - BA. Terreiro da Goméia mais antigo ainda em funcionamento, foi fundado em 1948, e atualmente é dirigido por Maria Lúcia Santana Neves, Mam'etu Kamurici, neta carnal de mãe Mirinha.
}

Periferia, v. 12, n. 3, p. 14-38, set./dez. 2020 


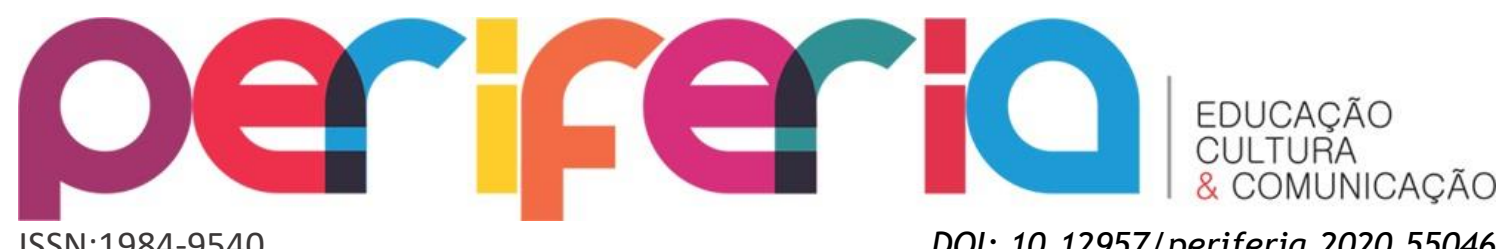
para a festa de Oxossi e um roncó ${ }^{8}$ repleto de filhas-de-santo. "A casa está cheia e o Roncó com 20 yaôs recolhidas. Por aí calcula como a minha cabeça está cheia também". ${ }^{9}$ No início do ano seguinte, mesmo com o falecimento de Bequê (ogan da Goméia), no mês anterior, 12 yaôs haviam saído recentemente do recolhimento, e ainda havia 2 para sair. ${ }^{10}$

Mesmo com tantas atribuições e preocupações em Caxias, Joãozinho não se furtava a ser um líder presente, ainda que à distância, da comunidade da Goméia em Salvador, dando assistência a assuntos de todas as ordens, desde a ocupação de imóveis na roça da Goméia de São Caetano (cartas 1 e 2) até assuntos estritamente pessoais (cartas 3 e 5). Ainda assim, as cartas revelam a circulação de Joãozinho no eixo São Paulo - Rio de Janeiro Salvador, (cartas 2, 5, 6, além da carta 7, de Maria Florença à mãe). Outro indício encontrado nas cartas reitera a imagem de que ele era um líder religioso que também apoiava financeiramente os membros de sua comunidade (cartas 4,5,7).

As cartas de Antônio Motta (cartas 8 e 9) foram enviadas no período dos dois anos seguintes à morte de Joãozinho, e tratam de questões vinculadas ao funcionamento das “duas Goméias” - de São Caetano, em Salvador, e de Duque de Caxias -, bem como sobre os assuntos da sucessão. Antônio José da Motta, comissário de polícia em Caxias, era uma figura de relevância no candomblé da Goméia, como se pode inferir nas fontes de imprensa do período. Integrante do terreiro da Goméia, Motta possuía uma relação de longa data com Joãozinho e aparecia com frequência nas notícias sobre o terreiro, especialmente durante o período de definição da sucessão imediatamente após a morte do pai de santo:

O Comissário Antônio Mota, da Delegacia de duque de Caxias, abrirá amanhã o cofre do falecido "babalorixá" Joãozinho da

\footnotetext{
${ }^{8}$ Roncó, camarinha: espaço sagrado, cômodo onde ficam reclusas as iniciadas e iniciados no candomblé.

${ }^{9}$ Carta 5 - Joãozinho a Maria Florença, 26 de junho de 1965

${ }^{10}$ Carta 6 - Joãozinho a Maria Florência, 8 de janeiro de 1966
}

Periferia, v. 12, n. 3, p. 14-38, set./dez. 2020 


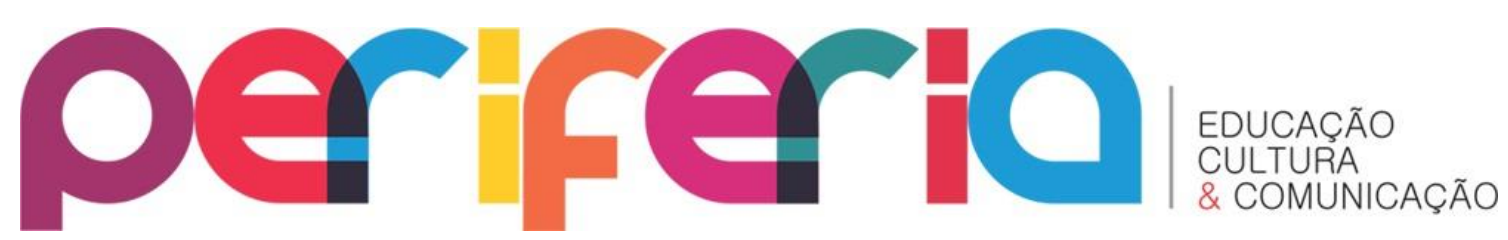

ISSN:1984-9540

DOI: $10.12957 /$ periferia. 2020.55046

Goméia (...). Nesse cofre, além das jóias do "papa" do candomblé no Brasil, está o testamento no qual Joãozinho da Goméia aponta o nome de seu sucessor. A casa, por medida de segurança, já se encontra sob forte vigilância policial. (Última Hora, 24/03/1971)

Não havia testamento no cofre, além de joias e incensos. A imprensa apressou-se, então, em afirmar que o jogo de búzios que deveria ser realizado para determinar a sucessão se tratava de uma decisão do comissário local:

Os búzios indicarão hoje, em Duque de Caxias, o sucessor de Joãozinho da Goméia, de acordo com a decisão do comissário Antônio Motta, da delegacia local, que se diz credenciado por dona Maria Vitorina Torres, mãe do babalaô. (Jornal do Brasil, 28/03/1971)

Ainda segundo a reportagem, Antônio Motta assegurava ter "delegação de poderes" da família de Joãozinho, para tomar todas as providências necessárias relativas à ordem das atividades no terreiro que levariam à indicação do possível sucessor.

Após aquele fatídico 28 de março de 1971, no entanto, seguiria longe a chamada "guerra de sucessão", fadada a não ter uma resolução definitiva enquanto existiu a Goméia de Caxias. Na qualidade de delegado do município e membro da Goméia, foi Motta, por sinal, quem orientou o caso no processo judicial que tentava impedir que a menina Seci Caxi assumisse o cargo de sucessora de Joãozinho, segundo Ziegler (1977, pp. 85-86). ${ }^{11}$

$\mathrm{Na}$ transição entre os anos de 1971 e 1972, com sinais de que a instabilidade na Goméia persistia, Paulo Sérgio Nigro, Dundum Ame, filho de santo de Joãozinho e dirigente de um terreiro em Del Castilho, concedeu uma entrevista onde afirmava que a Goméia estava “(...) em paz nas mãos de Antônio Mota (sic), que em apenas um mês fez o que ninguém conseguiu, em quase um ano" (Diário da Noite, 22/03/1972; O Jornal, 26/03/1972). “Não

\footnotetext{
${ }^{11}$ Sobre os acontecimentos relacionados ao axexê (rito funerário) de Joãozinho e a definição sobre a escolha de Seci Caxi como sucessora de Joãozinho, ver PEREIRA, Rodrigo. Análise do espaço e da cultura material no extinto terreiro da Goméia (Duque de Caxias/RJ): um estudo etnoarqueológico. Tese de Doutorado. Universidade Federal do Rio de Janeiro/ Museu Nacional, 2019, pp. 197-206.
}

Periferia, v. 12, n. 3, p. 14-38, set./dez. 2020 


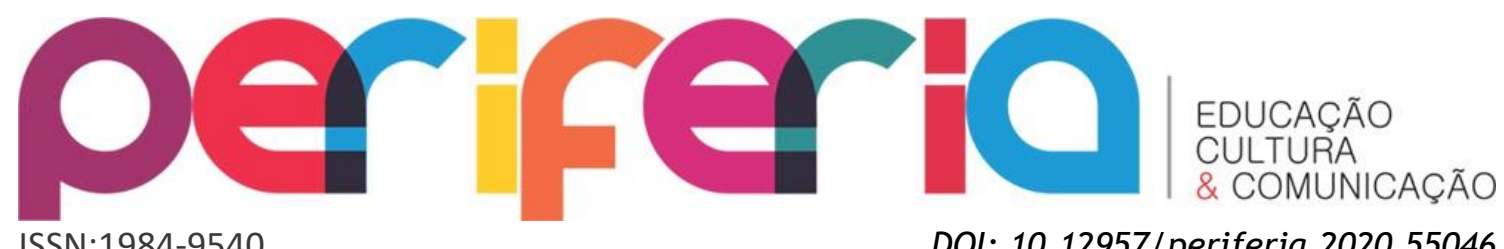

ISSN:1984-9540

DOI: $10.12957 /$ periferia. 2020.55046 existe crise", afirmou, fazendo referência aos comentários que corriam em Recife, onde uma das filhas de Joãozinho, Mãe Almerinda, também pleiteava o posto de sucessora do reinado da Goméia, e de onde surgiu a notícia de que o espírito de Joãozinho havia se "manifestado" e estava "infeliz" com os rumos que o terreiro de Caxias vinha tomando: “(...) Roubaram meu santo e despacharam o meu Egum na Goméia do Rio de Janeiro. Por isso, ela está fechada e jamais se levantará (...)" (0 Jornal, 21/03/1972). Àquela altura, Motta era considerado um dos dirigentes do terreiro, ao lado de Mãe Kitalamungongo e o alabê Valentim. "Antônio Mota, que sempre ajudou e foi amigo de Da Goméia, se encarrega da parte material", providenciando as ampliações necessárias para a realização do axexê, cerimônia fúnebre de um ano de morte do dirigente, segundo o próprio Dundum Ame. Naquela mesma semana, o jornal A Luta Democrática, ao anunciar a realização da cerimônia, afirmou que "(...) o ogan, procurador do rei do candomblé, Antônio Motta" iria promover um leilão público de joias e outros pertences de Joãozinho (A Luta Democrática, 25/03/1972).

Essas notícias revelam, em alguma medida, a importância do papel de Antônio Motta no andamento do terreiro após a morte de Joãozinho. No mês de dezembro de 1971 ele escreveu a José Daniel para tratar de assuntos referentes à sucessão da Goméia de São Caetano. Citando uma conversa com dona Senhora, mãe de Joãozinho, Motta explica que ela não tinha intenções de se envolver com assuntos referentes à Bahia e que, portanto, poderiam dar andamento a alguma providência legal que garantisse a ele e à Mãe Samba o direito de, em conjunto, assumirem efetivamente a direção da roça de São Caetano.

Mãe Samba Diamongo ${ }^{12}$ (Edith Apolinária Santana, ? - 1979) é uma das personagens do intrincado percurso de Joãozinho como pai de santo, raramente citada nos estudos sobre a Goméia, mas que merece especial

\footnotetext{
12 Em outras grafias, Diamungo, Diamungu, Ria Mungu. Optamos pela grafia Diamongo, forma escrita utilizada pela comunidade do terreiro fundado por ela, o Mansu Bantu Kuenkê Do Inkinamsaba, no bairro de Pirajá, em Salvador.
}

Periferia, v. 12, n. 3, p. 14-38, set./dez. 2020 


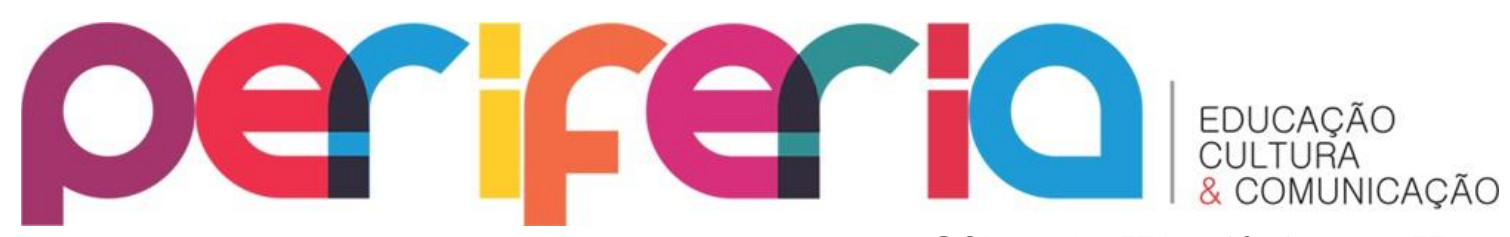

ISSN:1984-9540

DOI: $10.12957 /$ periferia.2020.55046 atenção por ter sido responsável, em larga medida, pela formação de Joãozinho como dirigente espiritual de um candomblé, além de ser "a outra ponta" do processo sucessório do pai de santo, no caso, a Goméia de São Caetano.

Mãe Samba foi iniciada no terreiro Manso Banduquenqué, o candomblé Bate-Folha de Salvador - BA, por Tata Ampumandezu (Manoel Bernardino da Paixão, 1892-1946), no terceiro barco de iniciadas, em 1933 (MENDES, 2014, p. 77). Diz-se de mãe Samba que, anteriormente à sua iniciação, chegou a frequentar o llê Axé Opô Afonjá, terreiro de nação ketu, mas ali se descobriu que a divindade para a qual deveria ser iniciada era um inquice da nação congo e, por esse motivo, foi aconselhada a procurar o Bate-Folha de pai Bernardino (RAMOS 2009, p. 261).

No início dos anos 1940, Mãe Samba já possuía seu terreiro na Fazenda Grande do Retiro, em Salvador, em uma localidade denominada Jaqueira do Carneiro, quando começou sua amizade com Joãozinho. A aproximação inicial talvez tenha se dado pelo fato de que Mãe Samba era costureira e confeccionava trajes em bordado richelieu ${ }^{13}$, mas é certo que os laços de amizade se estreitaram, a ponto de Joãozinho convidá-la para morar na roça da Goméia, onde havia duas casas, além do barracão do terreiro. Mãe Samba sofria com sucessivas perdas em função das inundações ocorridas pelo transbordamento do rio que passava próximo ao seu terreiro, no tempo das chuvas. (MENDES, 2014, p. 80).

Em várias narrativas, à amizade nascida entre pai Joãozinho e mãe Samba é creditado o desentendimento que a segunda teve com seu pai Bernardino, ele mesmo um desafeto do primeiro; no entanto, outros elementos compõe a trama desse conflito. A acusação de que Joãozinho não

\footnotetext{
13 “No candomblé, o richelieu surgiu como um elemento que conferia luxo às vestimentas, em função da sofisticação da técnica empregada (...). Se junta à joalheria ritual, assumindo um significado de "panojóia", e usado apenas em situações especiais, de festa, em contraposição ao despojamento das roupas de uso cotidiano." (MENDES, 2014, p. 100)
}

Periferia, v. 12, n. 3, p. 14-38, set./dez. 2020 


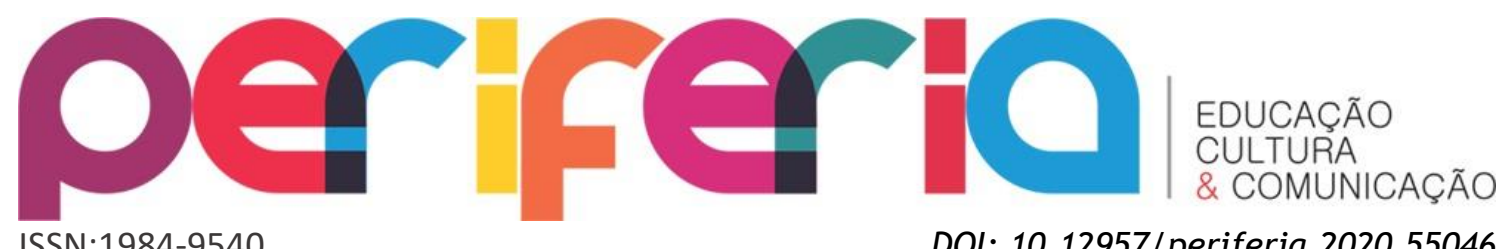
havia sido "feito" no santo, e a despeito disso ter assumido um papel de liderança no candomblé da Bahia, incomodava a muitos pais e mães de santo, podendo ter sido uma das causas do aborrecimento de Bernardino com sua filha de santo. Nesse caso, segundo o entendimento de Bernardino, mãe Samba teria se associado a alguém não legitimado dentro do candomblé (afora o fato de que o prestígio social e as repercussões sobre a vida de Joãozinho também eram fatores geradores de incômodo no conservador meio dos terreiros baianos). Outra narrativa sugere que o desentendimento tenha se dado em função de, ao se afastar do terreiro Bate Folha, mãe Samba ter levado consigo um caderno de anotações com registros dos fundamentos do terreiro - e, ainda pior, teria entregado esse caderno para Joãozinho da Goméia, traindo assim a confiança de Bernardino (NUNES, 2020, pp. 211, 213). Seja qual tenha sido a causa do rompimento entre mãe Samba e pai Bernardino, a figura de Joãozinho aparece direta ou indiretamente nas narrativas sobre o caso. ${ }^{14}$

A presença de mãe Samba na Goméia de Caxias é um tema que ainda carece de estudos, mas a imprensa documenta a importância dela após a morte de Joãozinho, tendo sido figura central na realização das cerimônias relativas ao axexê, tanto em Duque de Caxias quanto em Salvador, como se pode observar nos jornais da época. O Fluminense de 29/03/1971 aponta que mãe Samba iniciou o axexê na Goméia de Caxias, passando depois a responsabilidade para mãe lleci. O Jornal do Brasil de 03/04/1971 mencionou a presença dela nos funerais de Joãozinho, e a apontou como a mais provável sucessora do candomblé de São Caetano. O Globo de 29/03/1971 fez referência à mãe Samba como a sucessora escolhida pelo próprio Joãozinho, antes de sua morte.

O Correio da Manhã de 24/03/1971 se referiu a ela como “(...) a famosa mãe de santo que dirigiu os trabalhos do funeral de Joãozinho da

\footnotetext{
14 Diferentes versões e narrativas sobre as tensões entre Bernardino e mãe Samba, assim como entre Bernardino e Joãozinho, ver NUNES, Erivaldo Sales. Bate Folha: Trajetória e memória do candomblé de Bernardino. Salvador: Instituto Federal de Educação, Ciência e Tecnologia da Bahia, 2020
}

Periferia, v. 12, n. 3, p. 14-38, set./dez. 2020 


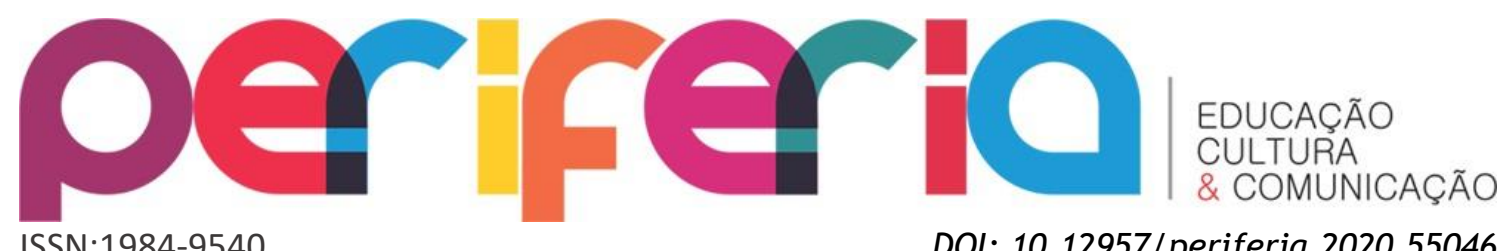

ISSN:1984-9540

DOI: 10.12957/periferia.2020.55046 Goméia". Àquela altura, o jogo de búzios de Tião do Irajá ainda não havia acontecido, e especulava-se que mãe lleci seria a "substituta mais provável". "[0] desejo de meu pai já foi confirmado pelos orixás, diz a velha baiana, através do jogo de búzios feito pela famosa mãe." Se de fato houve esse jogo, jamais saberemos, mas é fato que essa notícia nos dá pistas sobre o destaque do papel de Mãe Samba junto à Goméia de Caxias nos momentos imediatos que sucederam o falecimento de Joãozinho. Sobre a possibilidade de mãe lleci ocupar o trono da Goméia, vale lembrar que Antonio Motta afirmou, às vésperas do jogo realizado por Tião do Irajá (que definiu o nome da menina Seci Caxi como a herdeira do terreiro), que Joãozinho “(...) em vida e [por] várias vezes havia indicado mãe lleci como rainha do seu terreiro e sua substituta". Entender com clareza o posicionamento de Antônio Motta a respeito da sucessão na Goméia seria crucial para compreender de fato as motivações que o levaram a escrever para José Daniel, em abril de 1972.

Ao final do ano de 1971 já era certo que mãe Samba seria a sucessora de Joãozinho na Goméia de São Caetano. No mês de junho foi realizado o axexê em Salvador, presidido por Samba Diamungo, mas pelo menos desde o mês de maio já era sabido que ela seria a sucessora do terreiro: a escolha de seu nome parecia indiscutível, segundo uma notícia de imprensa. Diferente das tensões causadas pelo processo de sucessão na Goméia de Caxias, em Salvador não há registros de que a definição de Mãe Samba como sucessora tenha gerado conflitos, sendo bem aceita inclusive por Josefina Torres, uma prima-irmã de Joãozinho, residente na roça da Goméia com seus sete filhos, que recebeu "(...) com alegria a escolha (...), [fazendo] "muitos elogios à sua bondade, e ao carinho com que sempre zelou pelas coisas de Joãozinho". (Jornal do Commercio, 1 e 2/05/1971). É importante frisar que àquela época, Mãe Samba possuía seu próprio terreiro no bairro de Pirajá, em Salvador, o Mansu Bantu Kuenkê Do Inkinamsaba ${ }^{15}$, e que ela apenas continuaria cuidando da Goméia de São Caetano como já fazia anteriormente, com o deslocamento de Joãozinho para o Caxias.

\footnotetext{
${ }^{15}$ Ainda em funcionamento, o terreiro atualmente é dirigido por Mam'etu Marilda (Marilda Ferreira).
} 


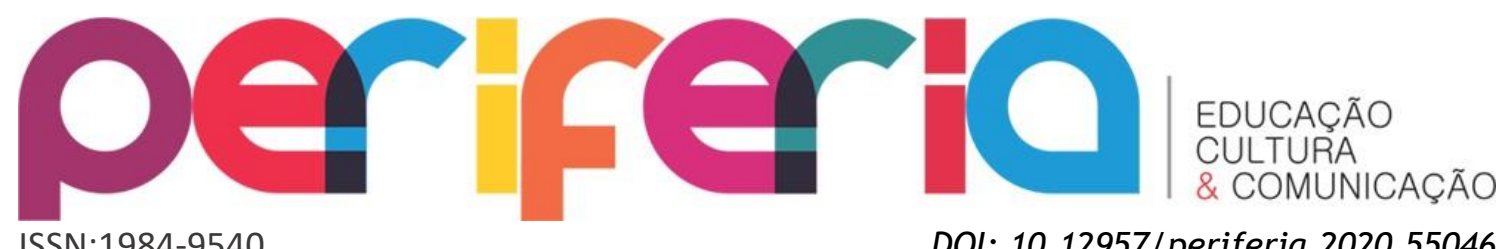

ISSN:1984-9540

DOI: $10.12957 /$ periferia. 2020.55046

Em março de 1972 foi realizada a cerimônia do axexê de primeiro aniversário da morte de Joãozinho. A imprensa da época deu destaque à presença de mãe Samba nos rituais, e a tentativa de confirmar o resultado do jogo realizado por Tião de Irajá, no ano anterior:

\begin{abstract}
“A cerimônia carioca em homenagem ao primeiro aniversário da morte de Joãozinho da Goméia (...) foi dirigida por Samba de Imu (sic) e Pai Belarmino, considerados os maiores pais-desanto da Bahia e outros nomes famosos do candomblé compareceram ao acontecimento (...) Os búzios (tiradores de sorte) fizeram novas tentativas para confirmar a indicação de Sandra Maria (sic), a Sessi Caxi, como herdeira de Joãozinho. A escolha de Sandra, no ano passado, causou espanto aos adeptos da seita, provocando, inclusive, uma grande crise no candomblé, porque a menina é muito nova, embora mãe Quitala e 0 alabê Valentim tivessem assumido a responsabilidade de suas ações (...) (0 Jornal, 21 de março de 1972)
\end{abstract}

Porém, a julgar pelo conteúdo da carta de Antonio Motta a José Daniel, apenas um mês após o axexê de um ano, não houve um jogo de búzios que tivesse confirmado de fato o jogo feito por Tião de Irajá: ele diz a José Daniel que a Goméia de Caxias necessitava da presença de mãe Samba na festa de Oxossi, que seria realizada na comemoração de Corpus Christis, como era tradição no terreiro. Aquela seria a primeira festa realizada na Goméia, depois de passado o período de luto que impedia a realização de festas públicas, como é costume no candomblé. Pede ainda que ele, Daniel, juntamente com mãe Samba, arranjassem "dois pais de santo famosos" para jogarem os búzios com pai Belarmino, "para ver se confirma o jogo do Tião de Irajá”, no dia seguinte dedicado à festa. Esse pedido dá mostras de que Motta acreditava que a presença de pais de santo baianos, "famosos", poderia dar mais legitimidade a um possível jogo que confirmasse o que havia sido determinado por Tião de Irajá, no ano anterior, confirmando assim a mentalidade de que a Bahia, afinal, era território dos "grandes" no candomblé.

Até pelo menos os primeiros sete anos após a morte de Joãozinho, Antonio Motta continuou na Goméia, assumindo posição de destaque no 


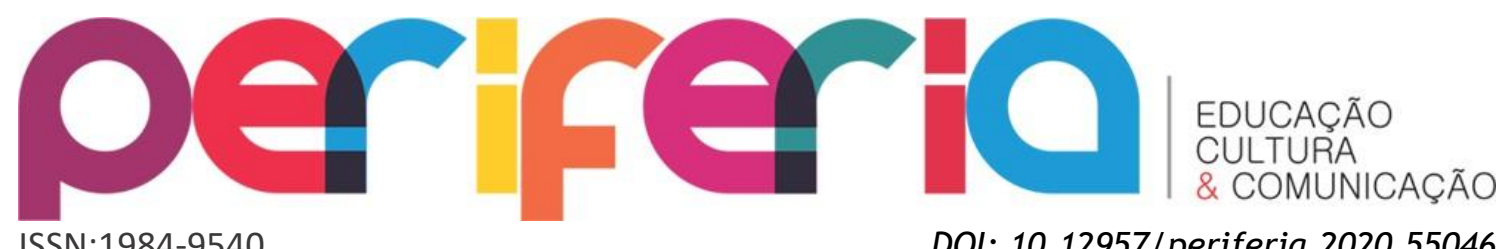

andamento dos assuntos referentes ao terreiro. Em outubro de 1977, foi criada uma "junta governativa” na Goméia de Caxias, transformada então em "sociedade civil de fins filantrópicos", presidida por Jitadê (Sebastião Paulo da Silva), e tendo as atividades do terreiro comandadas pelo "triunvirato" composto por Mãe Ileci, Kitala Mungongo e o ogan Valentim. Segundo o jornal "O Fluminense", quem vinha conduzindo as atividades do terreiro era Deuandá (Miguel Arcanjo Paiva, também conhecido como Miguel Grosso), mas que havia renunciado ao posto recentemente, naquela ocasião (O Fluminense, 14/10/1977). Segundo Gisele Cossard Omindarewa, quando o impasse sobre a sucessão havia se estabelecido, e não se chegava a um acordo sobre quem deveria assumir a direção do terreiro, foi decidido que Deuandá o faria, mas houve rejeição por parte da comunidade, o que provavelmente o fez renunciar ao posto (FICHTE 1987 p. 57). Cinco meses depois da criação da “junta governativa”, viria a acontecer o axexê pelo sétimo ano da morte de Joãozinho. É possível que essa “junta governativa” tenha sido criada precisamente em função da aproximação do aniversário de morte do pai de santo, para melhor organizar e levar a cabo os preparativos para o cumprimento dos rituais. A carta 9, enviada em 1978 pela ekedi ${ }^{16}$ Lurdes, $^{2}$ (Maria de Lurdes Ramos) comunicava a José Daniel (a quem trata como “amigo e irmão”) a data de realização da cerimônia fúnebre, informando que a passagem dele para ir a Caxias seria paga por Antônio Motta. Reforçou que o ogan Valentim mandava dizer que precisaria muito da ajuda dele nos rituais (lembrando que, como vimos anteriormente, Tata Daniel se tornou um especialista dos ritos fúnebres do candomblé Angola até o final de sua vida). Lurdes lamentou o fato de a comunidade da Goméia de Caxias não ter, naquele momento, recursos disponíveis para também garantir a vinda de mãe Samba, embora desejassem muito sua presença. Sobre Antônio Motta e seu papel no candomblé da Goméia de Caxias ainda são necessárias outras

\footnotetext{
${ }^{16}$ Ekedi: Similar à makota, dos candomblés Angola Kongo, é um cargo hierárquico feminino nos terreiros de candomblé. São mulheres que não entram em transe, escolhidas pela divindade do líder religioso, e assumem papel fundamental no andamento das atividades do terreiro, acompanhando a dança das divindades, de suas roupas sagradas, das filhas e filhos de santo, entre outras atribuições.
}

Periferia, v. 12, n. 3, p. 14-38, set./dez. 2020 


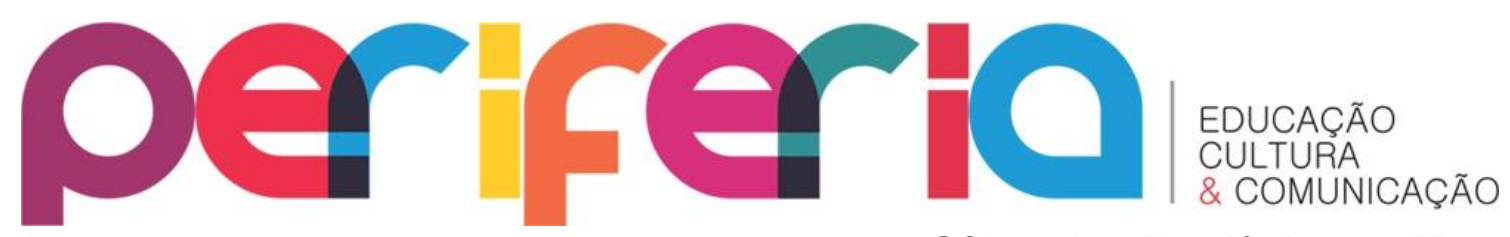

ISSN:1984-9540

DOI: $10.12957 /$ periferia. 2020.55046 investigações que se agreguem às informações que temos até agora, mas os indícios apontam para um papel de apoio financeiro e, devido ao seu posto de comissário de polícia, de influências sociais nada desprezíveis.

Finalmente, dentre os manuscritos do acervo de José Daniel, o de número 7, de Maria Florença à mãe, é a mais afetiva das cartas. Enviada em 1948, é a narrativa de uma jovem mãe que, em busca de melhores condições de vida, segue o mesmo fluxo de gerações inteiras no êxodo nordestino rumo ao sudeste. Deixando para trás um filho com onze anos incompletos aos cuidados da avó, Maria Florença, a comadre Neném de Joãozinho, narra eventos de seu cotidiano, sua fé nas divindades e a saudade que sente daqueles que deixou na Bahia. Possivelmente integrando o grupo de filhas de santo que acompanharam Joãozinho na migração para o estado do Rio de Janeiro, não morava em Caxias, mas na cidade do Rio - seria em função do trabalho que exercia ali? Como o destino de tantas imigrantes nordestinas no sudeste, é bem provável que Maria Florença vivesse no Rio trabalhando como empregada doméstica em uma casa de família.

Maria Florença faz referência a pessoas do convívio próximo de Joãozinho - Miranda, Bequê, Dona Neném. Essa “outra” Neném possivelmente se trata de dona Senhora, mãe de Joãozinho, pois, segundo mãe Luíza Tundaseli ${ }^{17}$, assim era chamada em Salvador. Miranda aparece na narrativa como alguém que se apresentava como "um bom amigo para elas todas" possivelmente fazendo referência às filhas de santo de Joãozinho, e também afirmando que era possível se viver "em paz" com ele. Talvez pelo fato - e aqui levantamos uma hipótese - de que Miranda assumidamente fosse alguém com quem pai João estivesse se relacionando amorosamente, com o conhecimento da comunidade e que, "ainda assim", fosse possível conviver com ele, na conservadora década de 1940. Miranda foi citado por Gisele Cossard Omindarewa como tendo sido "a paixão" da vida de Joãozinho e sua

\footnotetext{
17 Mãe Tundaseli é mam'etu ndenge do terreiro Mansu Bantu Kuenkê do Inkinamsaba. Agradeço especialmente à nengua de Nkisi Mãe Dango de Hongolo por intermediar o diálogo que culminou nessa informação).
}

Periferia, v. 12, n. 3, p. 14-38, set./dez. 2020 


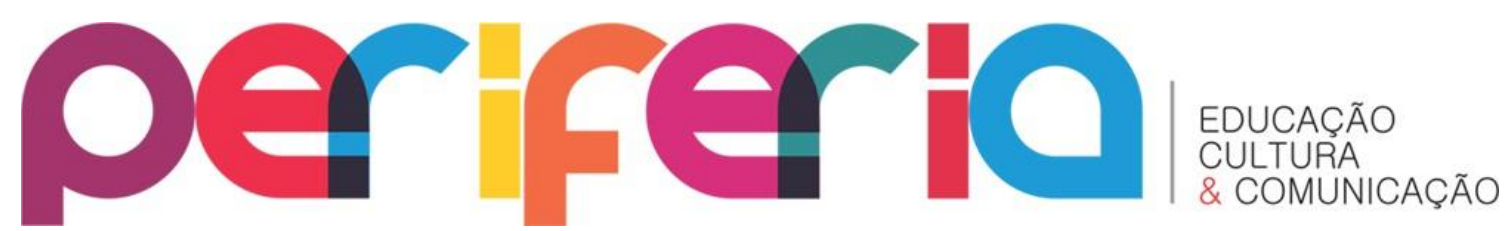

ISSN:1984-9540

DOI: $10.12957 /$ periferia.2020.55046

única relação mais duradoura, na juventude, a quem nunca teria esquecido (FICHTE 1987 p. 58).

Dentre outras narrativas, Maria Florença reforça o caráter paternal e cuidadoso de Joãozinho, e estende esse traço ao caboclo que o acompanhava: "Pedra Preta está sempre olhando pela senhora. Seu Pedra Preta me fez uma caridade que eu não esperava. Ele está sempre olhando por mim".

As cartas aqui apresentadas possuem um vasto potencial de análise, e procurei assinalar rapidamente alguns dos temas que podem ser explorados, especialmente a partir do entrecruzamento de fontes relativas à comunidade da Goméia, seu fundador e seus integrantes. Para contextos de pequenos grupos, como é o caso aqui apresentado, arquivos pessoais se mostram como grandes mantenedores de informações e dados históricos a serem indagados. Nesse sentido, é importante que tais acervos, habitualmente dispersos e desconhecidos, sejam disponibilizados não somente à comunidade acadêmica, mas especialmente à sociedade em geral. Além de se caracterizarem como depositários da memória afetiva de seus possuidores, coleções particulares podem e devem ser tratadas como patrimônios que a sociedade merece conhecer.

\section{As cartas}

\section{1 - Carta de Joãozinho a Maria Florência (manuscrita)}

(sem data)

Sua saúde é que desejo, como vai José, aqui todos bons graças ao bom Deus. Nenem fiquei muito contrariado quando soube que você alugou a casa sua aí na roça, você dê um jeito em mandar a pessoa mudar pois eu não quero gente estranha aí na roça, não vê a minha[,] eu ponho gente para morar mas não alugar, se você não quer morar feche a casa[,] mas alugar não, eu

Periferia, v. 12, n. 3, p. 14-38, set./dez. 2020 


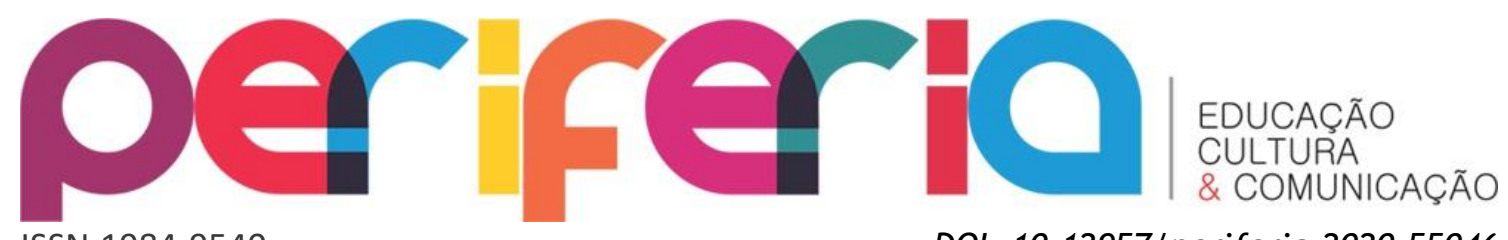

ISSN:1984-9540

DOI: $10.12957 /$ periferia.2020.55046

chegando aí vou me aborrecer muito. Sem mais aceite um abraço do compadre

João Dagoméa

\section{2 - Carta de Joãozinho a Maria Florença (manuscrita)}

Caxias 12 de Março 57

Comadre Nenem.

Recebi sua cartinha e estou ciente de tudo[,] como vai Zefa e o José[?] lembranças a todos[.]

[E]u devo ir no principio de Maio se Deus quiser[,] todos em aqui em paz e mandam lembranças.

Como vai Dotor, a parenta de Pedro Velho já apareceu para acertar o negocio da casa?

Sem mais[,] abraços[,] saudades do compadre João.

[nota na margem esquerda: Nenem me faça o favor de entregar essa carta a Berenice de Nininha com urgência]

\section{3 - Carta de Joãozinho a Maria Florença (datilografada)}

Caxias, 26 de maio de 1962

Prezada Comadre Néné

Respondo à sua carta de 9 de maio, fazendo votos pela sua saúde e de todos. 


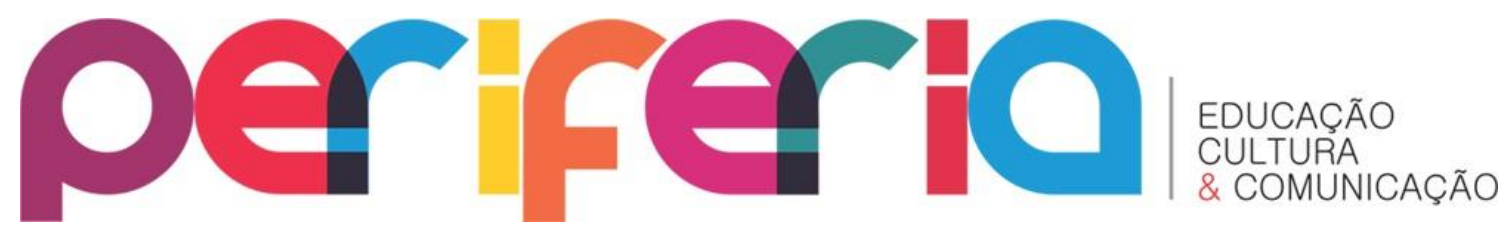

ISSN:1984-9540

DOI: 10.12957/periferia.2020.55046

Li tudo o que me manda dizer e só posso aconselhar a ter paciência. Aqui farei o que for possível junto aos orixás, para levar paz à sua vida.

Em 2 de julho estarei ai para a festa do Sr. Pedra Preta e então falaremos mais à vontade sobre o assunto.

Dê por mim lembranças a todos e receba um grande abraço do compadre e amigo

João Dagoméa

a benção para José

\section{4 - Carta de Joãozinho a José Daniel (datilografada)}

Caxias, 28 de maio de 1964

Prezado afilhado José,

Recebi sua carta que agradeço e li com a maior atenção.

Notei tudo que me manda dizer e peço que vá fazendo aí o que puder de acordo com as necessidades mais urgentes.

Aproveitando um portador, o sr. Costa, remeto cruzeiros cincoenta mil, que peço me acuse o recebimento e me vá dando notícias do que está fazendo.

Como hoje é dia de Oxosse e a casa está cheia de gente, sendo a festa logo mais, não posso escrever muito.

Receba a bênção e um abraço do padrinho e amigo

Joãosinho Dagomea

5 - Carta de Joãozinho a Maria Florença (datilografada)

Periferia, v. 12, n. 3, p. 14-38, set./dez. 2020 


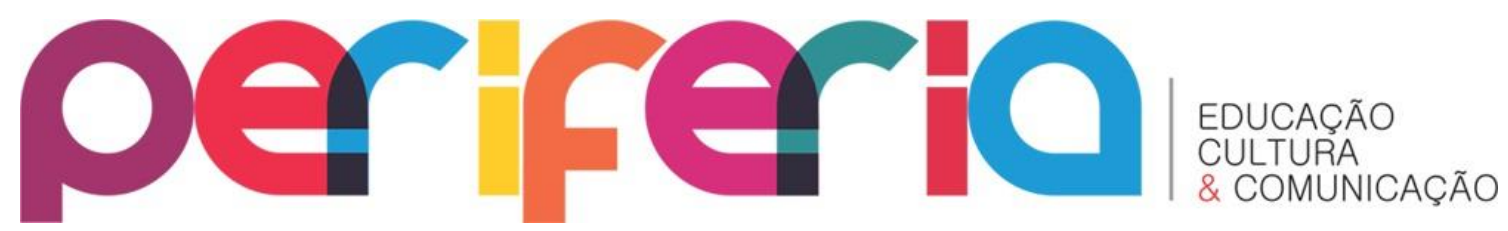

ISSN:1984-9540

DOI: $10.12957 /$ periferia.2020.55046

Caxias, 26 de junho de 1965

Prezada comadre Nenê,

Respondo sua carta de 17 de maio com um pouco de atraso, pois estive 3 semanas em São Paulo para uma obrigação de um filho de Santo e logo que cheguei começaram as obrigações para a festa de Oxosse que foi dia 17 deste mês. A casa está cheia e o Roncó com 20 yaôs recolhidas. Por aí calcula como a minha cabeça está cheia também.

Mamãe também foi operada da vista e[,] embora esteja passando bem, graças a Deus, me deu muita preocupação.

Fiquei muito preocupado e surpreso com o que me conta em sua carta sobre José.

Se estivesse aí seria mais fácil chamá-lo e ter uma conversa com ele, fazendo ver a sua responsabilidade como chefe de família, mas assim de longe, vou escrever para ele dando alguns conselhos.

Farei o que puder para lhe ajudar.

Sobre Agaunsi, está certo o que fez e em vista de já estar aí, pode ficar até arranjar um lugar e trabalho ou amparo. Mande dizer se precisa alguma coisa que mandarei a ajuda que puder.

Espero que em breve tudo se acalme e faço voto para que tenham paz e saúde.

Receba um grande abraço do seu compadre amigo

João Dagoméa

\section{6 - Carta de Joãozinho a Maria Florença (datilografada)}

Caxias, 8 de janeiro de 1966

Periferia, v. 12, n. 3, p. 14-38, set./dez. 2020 


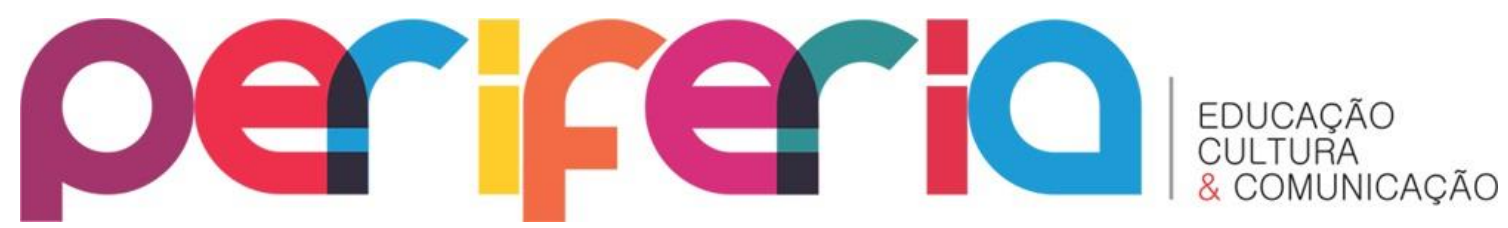

ISSN:1984-9540

DOI: $10.12957 /$ periferia.2020.55046

Prezada comadre Nenen,

Recebi sua carta de 17 de dezembro e fiquei ciente de tudo que me conta.

Já está a par do falecimento do Bequê no dia de Natal, pois mandei telegrama avisando.

Infelizmente não posso ir aí agora em janeiro como tinha planejado, porque o Axexê vai começar dia 18 e até agora tenho Yaôs recolhidas. Já saíram 12 e tem mais 2 para sair antes do Axexê.

Quando eu puder ir the avisarei e qualquer coisa me escreva.

Envio lembranças a todos e um abraço do compadre e amigo João Dagoméa

\section{7 - Carta de Maria Florença à sua mãe (manuscrita)}

Rio, 4 de Julho de 1948

Querida mãe

Desejo à Senhora e meu filho José, muita saúde e felicidades.

Eu graças a Deus e os santos, vou com saúde e trabalhando, como sempre trabalhei, mas felizmente não tem faltado nada, as saudades que tenho da senhora e José é que devora meu coração, já não aguento mais. Espero carta da senhora este mês, pois quero notícias de todos. Pretendo ir em Agosto, peça a Deus e Ogum por mim, sei que Oxum não me abandona. Cuidado com José. Diz ao Mundinho que estou longe, mas fico sempre agradecida por ele pedir ao santo por mim.

Periferia, v. 12, n. 3, p. 14-38, set./dez. 2020 


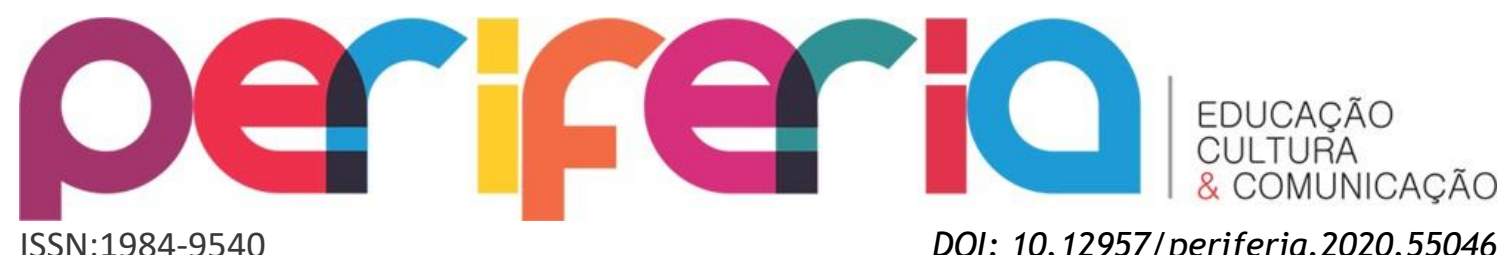

A Da. Anisia que é sempre bondosa e gentil desejo a ela muita felicidade e saúde. Tenho também saudades do Joãosinho, desejo que ele esteja bem de saúde. A Da. Nenen estou sempre com ela, somos muito amiga[s].

Pode remeter as minhas cartas para casa dela, que é o endereço seguinte:

Rua Neri Pinheiro número 110 - Estacio de Sá. Recomendações a Chica, Vovó, Bêquê, a velha Barba Fafá e todos mais que perguntarem por mim.

Eu fui ao aniversario de Miranda passar com todos em paz. A morte das três, não foi falta de cuidado, e sim porque Deus quis, pois o João foi um verdadeiro pai, fez um enterro como filhas de gente rica.

O Miranda também tem sido um bom amigo para elas todas.

A Da. Nenen envia abraços a senhora.

João em Novembro ou Dezembro vai à Bahia fazer a festa de lansã, o sirrum das meninas e tratar dos negócios dele pois ele tem sempre boa vontade de amparar a todos que estão aí na roça.

Pedra Preta está sempre olhando pela senhora. Seu Pedra Preta me fez uma caridade que eu não esperava. Ele está sempre olhando por mim.

Quando eu for, passo telegrama.

Termino enviando muitos beijos a meu filho José e para a senhora. Abraços e uma benção que the pede a filha

Maria Florença

\section{8 - Carta de Antônio Motta a José Daniel (datilografada)}

Rio de Janeiro, 17 de dezembro de 1971

Periferia, v. 12, n. 3, p. 14-38, set./dez. 2020 


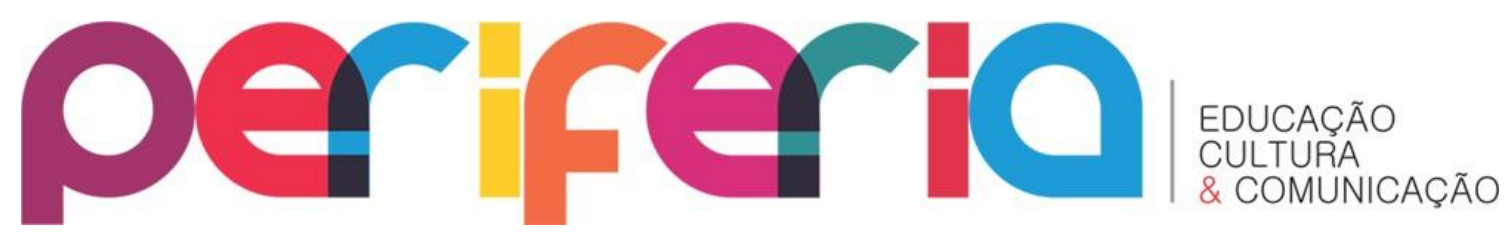

Caro amigo JOSÉ DANIEL

Estimo que ao receber esta, você esteja se preparando para um dos melhores Natais de toda a sua vida, muito embora, ainda pesaroso com a perda irreparável de nosso estimado Joãozinho.

Daniel, estive com D. Senhora e falei muito sobre a GOMÉIA da Bahia, e ela me disse não ter nenhum a intenção de se envolver com coisas concernentes ao que se passa aí. Sendo assim, creio não haver nada que o impeça de procurar o Dr. ALMIR, para que ele dê andamento ao requerimento em seu nome, para que você juntamente com Mãe Samba tomem conta da roça.

Espero em Deus, poder estar aí com vocês, na ocasião do Axexê de um ano para manter um entendimento pessoal.

Sem mais para o momento, quero renovar meus votos de um venturoso Natal e um Ano novo de Paz e amor.

Um grande abraço do amigo

Antônio José da Motta

9 - Carta de Antônio Motta a José Daniel (manuscrita)

Caxias, $24 / 4 / 72$

Caro amigo José Daniel.

Estimo que ao receber esta esteja com saúde juntamente com todos seus.

Periferia, v. 12, n. 3, p. 14-38, set./dez. 2020 


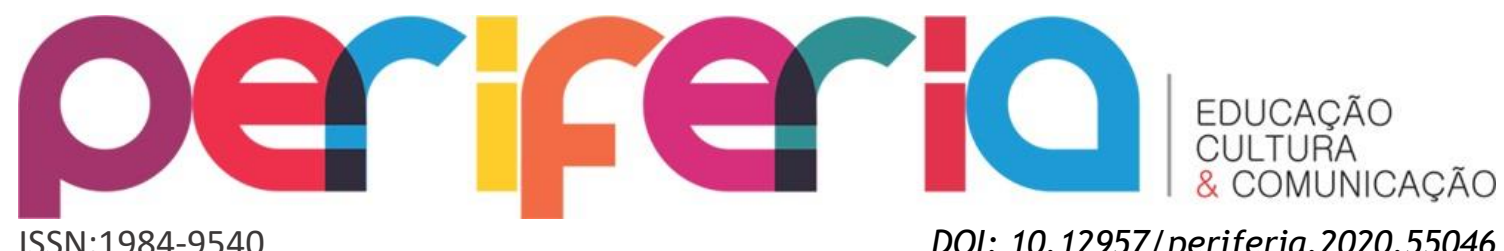

ISSN:1984-9540

DOI: 10.12957/periferia.2020.55046

Daniel, gostaria que você me fizesse um grande favor, é que precisamos que a mãe Samba venha para a festa do nosso pai Oxoce, se você puder vir eu ficaria muito contente;

Entre tanto, gostaria que você mandasse me dizer se ela pode vir para que eu mande a passagem, e se posso mandar para esse endereço, e peço um grande favor - de ver se você com a mãe Samba conseguem uns 2 pais de santo famosos para jogarem os búzios juntamente com sr. Belarmino, para ver se confirma o jogo do Tião do Irajá. Isto será feito no dia 2 de junho porque a festa de Oxoce será no dia $1^{\circ}$ de junho (corpus christis)[.]

Sem mas, queiram aceitar um forte abraço, e aguardo resposta urgente. Antonio Motta.

10 - carta da ekede Lurdes a José Daniel (manuscrita)

Rio, 1. 3. 78

Prezado amigo e irmão José Daniel

Venho por meio desta, comunicar que o axexê de pai João começa dia 12 de março e termina no dia 19 [de] Março;

Quanto à passagem para buscar a ebame Mãe Samba, o povo não tem, e Antônio Motta falou que a sua passagem ele paga.

Aqui todos estão lhe aguardando e o Ogan Valentin manda dizer para você vir sem falta, pois ele precisa muito de você para ajudá-lo. Queríamos que ebame Samba viesse mais não temos condições para mandar buscá-la.

Sem mais[,] um abraço para sua mãe, e sua esposa e filhos. De sua irmã Ekede Lurdes

Periferia, v. 12, n. 3, p. 14-38, set./dez. 2020 


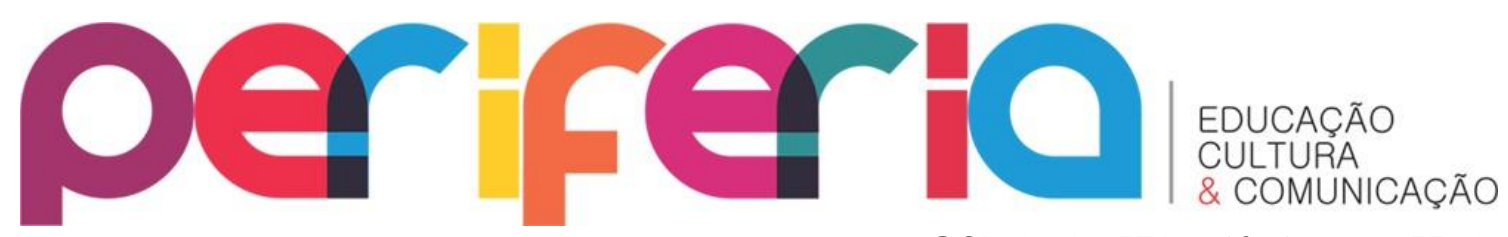

Rua Bangu (312) 312. Bairro Dr. Laureano D. Caxias

\section{Referências}

Fontes primárias

Acervo pessoal de José Daniel das Neves (dig.)

Fontes impressas (Biblioteca Nacional Digital)

A Luta Democrática

Diário da Noite

Jornal do Brasil

O Fluminense

Última Hora

\section{Referências Bibliográficas}

FICHT, Hubert. Etnopoesia - Antropologia poética das religiões afroamericanas. São Paulo: Brasiliense, 1987

GINZBURG, Carlo. Mitos, Emblemas e Sinais. São Paulo: Cia. das Letras, 1989

GOMES, Angela de Castro (org). Escrita de si, escrita da História. Rio de Janeiro: Fundação Getúlio Vargas, 2004

MENDES, Andrea. Vestidos de Realeza. Fio e nós centro-africanos no candomblé de Joãozinho da Goméia. Duque de Caxias, RJ: APPH-CLIO, 2014

NUNES, Erivaldo Sales. Bate Folha: Trajetória e memória do candomblé de Bernardino. Salvador: Instituto Federal de Educação, Ciência e Tecnologia da Bahia, 2020 


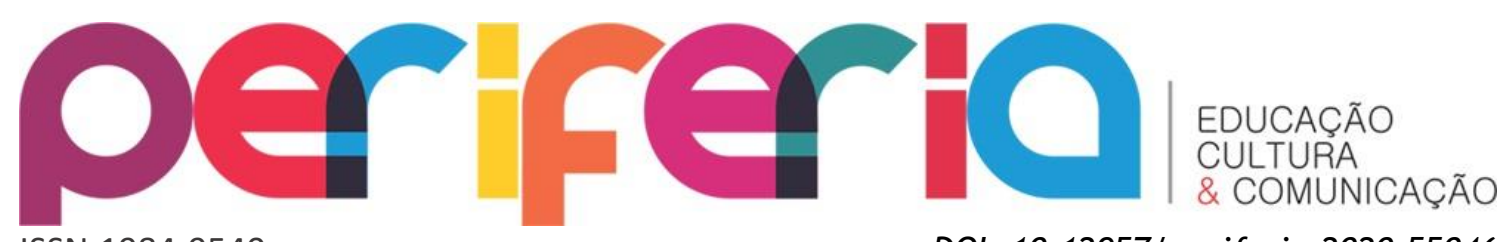

ISSN:1984-9540

DOI: $10.12957 /$ periferia.2020.55046

PEREIRA, Rodrigo. Análise do espaço e da cultura material no extinto terreiro da Goméia (Duque de Caxias/RJ): um estudo etnoarqueológico (Tese de Doutorado). Museu Nacional, Programa de Pós Graduação em Arqueologia. Rio de Janeiro: Universidade Federal do Rio de Janeiro, 2019

RAMOS, Cleidiana. O discurso da luz: imagens das religiões afro-brasileiras no arquivo do jornal "A Tarde". Dissertação de mestrado. FFCH-Programa de Pós Grduação em Estudos Étnicos e Africanos. Salvador: Universidade Federal da Bahia, 2009

ZIEGLER. Jean. A Morte na Goméia. In Os vivos e a morte. Rio de Janeiro: Zahar Editores, 1977, pp. 71-90 